\title{
Correction to: New insights into the rainfall variability in the tropical Andes on seasonal and interannual time scales
}

\author{
Hans Segura ${ }^{1}\left(\right.$ Clementine Junquas $^{1} \cdot$ Jhan Carlo Espinoza $^{1,2}$ (1) Mathias Vuille $^{3} \cdot$ Yakelyn R. Jauregui $^{4}$. \\ Antoine Rabatel ${ }^{1} \cdot$ Thomas Condom $^{1} \cdot$ Thierry Lebel $^{1}$
}

Published online: 11 January 2021

○) Springer-Verlag GmbH Germany, part of Springer Nature 2021

\section{Correction to: Climate Dynamics}

https://doi.org/10.1007/s00382-018-4590-8

The original version of the article contained errors in

Fig. 10. The correct Fig. 10 is shown below.

The original article can be found online at https://doi.org/10.1007/ s00382-018-4590-8.

\footnotetext{
Hans Segura

hans.segura@univ-grenoble-alpes.fr

1 Univ. Grenoble Alpes, IRD, CNRS, Grenoble INP, IGE

(UMR 5001), 38000 Grenoble, France

2 Instituto Geofsico del Per (IGP), Lima, Peru

3 Department of Atmospheric and Environmental Sciences, State University of New York At Albany, Albany, NY, USA

4 Department of Atmospheric Sciences, University of Washington, Seattle, USA
} 

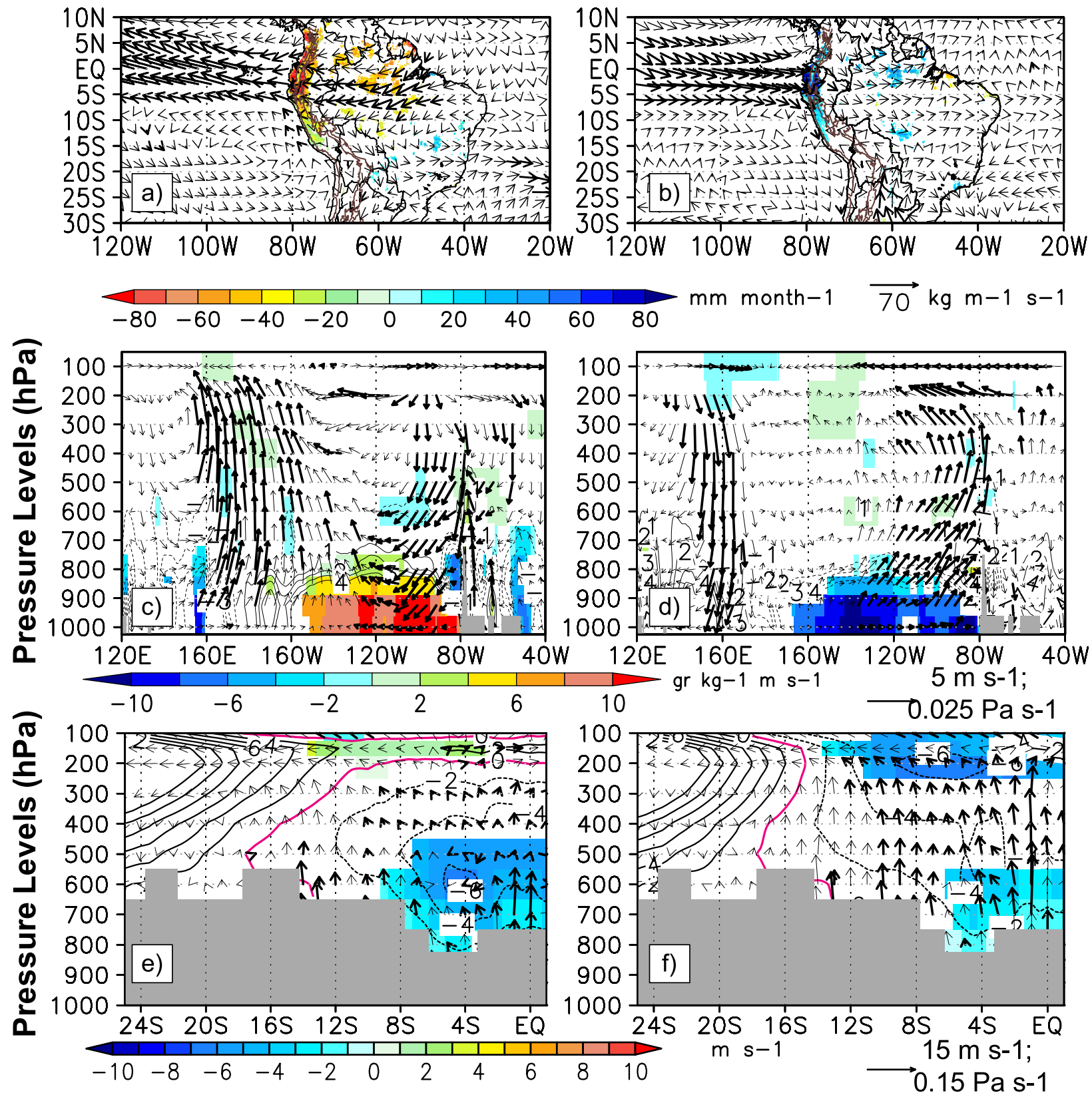

Fig. 10 a Composite for CHIRPS precipitation (shaded) and vertically integrated water vapor flux (vectors) anomalies considering dry events from February to April (FMA) in the equatorial Andes (PCE1). Only significant precipitation anomalies are shown and bold vectors represent significant meridional or zonal vertically integrated water vapor flux anomalies. Topography contours (black bold lines) are the same as in Fig. 1. c Pressure-longitude cross-section at $0^{\circ} \mathrm{N}$ for anomalies of meridional humidity transport (contours; $\mathrm{q} x \mathrm{v}$ ), and zonal-vertical wind velocity (vectors) for dry FMA events in the equatorial Andes. Positive (negative) meridional moisture transport anomalies are represented by solid (dashed) lines and only significant values are shaded. Bold vectors represent significant vertical or

Publisher's Note Springer Nature remains neutral with regard to jurisdictional claims in published maps and institutional affiliations. zonal wind anomalies. Andes profile at $0^{\circ} \mathrm{N}$ is shown in gray. e Pressure-latitude cross-section of mean zonal wind (contours) and mean meridional-vertical wind (vectors) averaged over the tropical Andes for dry FMA events in the southern tropical Andes. The zonal mean only takes into account wind data between 2000 m.a.s.l. on the western Andes slope and 350 m.a.s.l. on the eastern Andes slope. Positive (negative) mean zonal winds values are drawn by solid (dashed) lines and only grid points with significant anomalies are shaded. Bold vectors represent significant meridional or vertical winds. The average zonal profile of the Andes is shown in gray. $\mathbf{b}, \mathbf{d}, \mathbf{f}$ similar to $\mathbf{a}, \mathbf{c}, \mathbf{e}$, respectively, but for wet FMA events 